\title{
Analisis Tarif Rumah Sakit dan Tarif Ina CBGs Kasus Gagal Jantung Kongestif
}

\section{Analysis of Hospital Inpatient Costs and INA-CBGs Tariffs for Congestive Heart Failure}

\author{
Nina Dwi Astuti ${ }^{1}$ \\ Irmawati $^{2}$ \\ Apifah $^{3}$ \\ Jurusan Rekam Medis dan Informasi Kesehatan Poltekkes Kemenkes Semarang \\ Dengan alamat Jl. Tirto Agung, Pedalangan, Banyumanik, Semarang \\ E-mail :rmik@poltekkes-smg.ac.id
}

\begin{abstract}
Hospital inpatient costs and INA-CBGs tariffs are different as these payment mechanisms are calculated using different parameters. If there is a huge difference, it can disadvantage hospitals, especially the private ones that take profits as one of the most concerning aspects. This study on congestive heart failure used a cross-sectional design. It was conducted at a type-C private hospital in Central Java province. As many as 70 congestive heart failure cases were analyzed using a univariate analysis to identify characteristics of the samples, a difference of hospital inpatient costs and INA-CBGs tariffs, and components of hospital inpatient costs. The analysis of factors contributing to the cost difference was done by calculating a weighted index based on the severity level, patient classes, Length of Stay (LOS), number of treatment types, and secondary diagnosis. The results show high-cost difference was found in patients who underwent treatment in more than 5 days and received more than one type of treatment. Treatment that lasted for more than 5 days caused hospital inpatient costs higher at $102 \%$ compared to INA-CBGs tariffs, while more than one type of treatment (another treatment besides electrocardiography) cause hospital inpatient costs higher at $65 \%$ than INA-CBGs tariffs. The implementation of the clinical pathway can be considered for service efficiency. This method can reduce the duration of inpatient care and unnecessary treatment regardless of the service quality.
\end{abstract}

Keywords: hospital inpatient costs; INA-CBGs tariffs

\begin{abstract}
Abstrak
Tarif rumah sakit dan tarif Ina CBGs mengalami perbedaan karena perhitungan kedua tarif tersebut menggunakan parameter yang berbeda. Namun jika perbedaan tersebut menyebabkan selisih yang besar, dapat menimbulkan dampak kerugian bagi rumah sakit. Permasalahan ini terutama pada rumah sakit swasta yang harus memperhatikan profit. Penelitian pada kasus Gagal Jantung Kongestif dengan studi cross sectional dilakukan pada salah satu rumah sakit swasta tipe $C$ di Jawa Tengah. Sebanyak 70 kasus gagal jantung kongesif dianalisis secara univariat untuk mengetahui karakteristik sampel, perbedaan tarif rumah sakit dengan tarif Ina CBGs, dan komponen tarif rumah sakit. Analisis faktor yang dapat menyebabkan perbedaan tarif dilakukan dengan menghitung angka indeks tertimbang berdasarkan severity level, kelas rawat, lama hari rawat, jumlah tindakan dan diagnosa sekunder. Hasil menunjukkan bahwa perbedaan tarif yang tinggi terdapat pada lama hari rawat $>5$ hari dan jumlah tindakan $>1$. Lama hari rawat $>5$ hari menjadi faktor yang menyebabkan tarif rumah sakit lebih tinggi $102 \%$ dari pada tarif Ina CBGs, sedangkan jumlah tindakan lebih dari satu (ada tindakan selain EKG)
\end{abstract}


menyebabkan tarif rumah sakit lebih tinggi 65\% dari pada tarif Ina CBGs. Penerapan clinical pathway dapat dilakukan untuk efisiensi pelayanan. Penggunaan clinical pathway dapat menurunkan lama hari rawat dan tindakan yang kurang diperlukan tanpa mengurangi kualitas pelayanan.

Kata kunci: biaya rumah sakit; tarif Ina CBGs

\section{Pendahuluan}

Perbedaan tarif rumah sakit dengan tarif INA CBGs dengan selisih negatif yang besar masih menjadi persoalan pembiayaan di rumah sakit. Beberapa penelitian telah menunjukkan adanya selisih ini. Penelitian di RSUD Sultan Syarif Muhammad Pontianak mendapatkan hasil bahwa terdapat selisih negative biaya riil dengan tarif INA CBGs pada pasien stroke iskemik dengan kode I63.9. (Cahyani, 2019). Demikian juga penelitian Putra (2014) yang menyatakan bahwa pada kasus-kasus bedah, kecenderungan biaya INA CBGs lebih rendah dari biaya riil rumah sakit. Bagi rumah sakit swasta yang harus memperhatikan profit, tentu menjadi tantangan tersendiri. (Danuarsa, 2019). Kasus-kasus berbiaya tinggi dengan selisih tarif negatif yang cukup besar antara tarif riil rumah sakit dan tarif INA CBGs berpotensi menimbulkan kerugian bagi rumah sakit. (Aisyah, 2018).

Tarif rumah sakit bersumber pada data costing rumah sakit dan ditetapkan sesuai tujuan penetapannya. Untuk rumah sakit swasta dengan tujuan profit, tarif merupakan unit cost yang telah ditambahkan dengan keuntungan yang ingin didapatkan. (Tristantoro, 2016).

Tarif INA-CBGs merupakan tarif paket yang perhitungannya didasarkan pada data costing dan data koding rumah sakit. Data costing didapatkan dari data rumah sakit terpilih yang menjadi representasi rumah sakit, sedangkan data koding merupakan kode Ina CBGs. Besaran tarif berbeda berdasarkan regionalisasi wilayah dan kelas rumah sakit. Sedangkan grouping Ina CBGs dengan memperhatikan diagnosa, prosedur dan severity level.
Penyakit katastropik merupakan penyakit dengan biaya pelayanan kesehatan yang tinggi. Beberapa penyakit yang termasuk penyakit katastropik adalah penyakit gagal ginjal, penyakit jantung, kanker, serta penyakit kelainan darah yaitu thalassemia dan hemophilia (Heniwati, 2016). Menurut data Organisasi Kesehatan Sedunia (WHO), penyakit kardiovaskular adalah penyebab utama kematian di seluruh dunia. Pada tahun 2012 diperkirakan 17,5 juta orang meninggal karena penyakit kardiovaskular (WHO, 2015).

Gagal jantung merupakan tahap akhir dari seluruh penyakit jantung dan merupakan penyebab peningkatan morbiditas dan mortalitas pasien jantung. Kecenderungan insiden gagal jantung meningkat karena faktor usia, hipertensi, dislipidemia, dan diabetes. Insiden gagal jantung pada usia $<45$ tahun adalah $1 / 1000$. Pada usia $>65$ tahun meningkat menjadi $10 / 1000$, dan pada usia >85 menjadi 30/1000. (Rahma, 2014).

Pada kasus Gagal Jantung Kongestif di rumah sakit $X$ pada bulan OktoberDesember 2019, terdapat perbedaan antara tarif riil rumah sakit dengan tarif INACBG's. Jumlah selisih tarif riil dengan tarif INA CBGs bernilai negatif yaitu sebesar 40.158.430. Jumlah tersebut tentu dapat menimbulkan kerugian bagi rumah sakit. Menganalisis perbedaan tarif rumah sakit dengan tarif INA CBGs kasus kegagalan jantung menjadi hal penting untuk dilakukan.

Telah banyak penelitian tentang perbedaan tarif rumah sakit dengan tarif INA CBGs, namun sebagian besar merupakan penelitian deskriptif yang 
hanya menjelaskan besarnya selisih tarif. Menganalisis lebih mendalam untuk mengetahui komponen biaya dengan selisih yang tinggi dapat dilakukan untuk mengetahui faktor penyebab terjadinya selisih tarif dan sebagai bahan masukan untuk evaluasi pembiayaan di rumah sakit.

\section{Metode}

Penelitian ini merupakan penelitian kuantitatif dengan pendekatan cross sectional. Sebanyak 70 sampel diteliti dan merupakan keseluruhan kasus gagal jantung kongesif dari laporan klaim BPJS Kesehatan bulan Oktober - Desember 2019 pada rumah sakit swasta tipe $\mathrm{C}$ di Jawa Tengah. Analisis univariat dengan distribusi frekuensi disajikan untuk mengetahui karakteristik sampel penelitian, perbedaan tarif rumah sakit dengan tarif Ina CBGs dan komponen pembentuk tarif rumah sakit. Perbedaan selisih tarif berdasarkan severity level, kelas rawat, lama hari rawat, tindakan, dan diagnosa sekunder dianalisis menggunakan angka indek tertimbang untuk mengetahui faktor yang mempengaruhi selisih tarif dengan komponen biaya yang tinggi.

Variabel terikat dalam penelitian ini adalah selisih tarif yang merupakan selisih tarif Ina CBGs dibandingkan dengan tarif rumah sakit. Sedangkan variable terikat adalah severity level kasus gagal jantung kongesif (level I, II, dan III), kelas rawat (1, 2 dan 3), lama hari rawat dengan kategori LOS $\leq 5$ hari dan $>6$ hari $($ ALOS $=5$ hari), tindakan dengan kategori 0-1 jenis tindakan (tanpa tindakan atau hanya EKG) dan $>1$ jenis tindakan (terdapat tindakan lain selain EKG), dan diagnosa sekunder dengan kategori adanya diagnosa sekunder kasus sistem kardiovaskuler dan tidak adanya diagnosa sekunder kasus sistem kardiovaskuler.

\section{Hasil dan Pembahasan}

Karakteristik umum pada kasus Gagal Jantung Kongestif yang diteliti dalam penelitian ini adalah sebagai berikut :

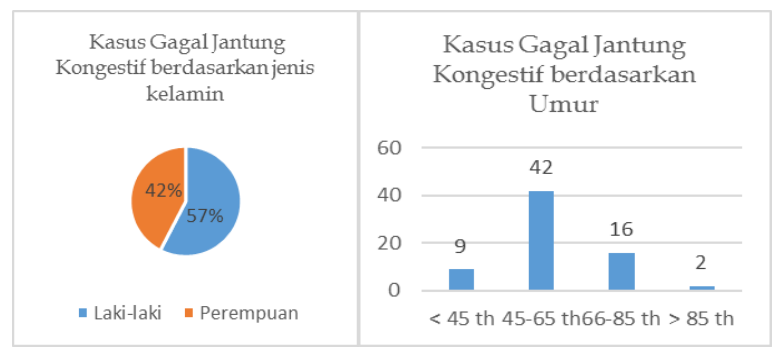

Gambar 1. Kasus Gagal Jantung Kongestif Berdasarkan Jenis Kelamin dan Umur

Sebagian besar kasus Gagal Jantung Kongestif yang diteliti dialami oleh laki-laki (57\%), namun jumlah tersebut hampir seimbang terhadap perempuan. Beberapa penelitian juga mendapatkan hasil yang sama dimana kasus gagal jantung yang ditemukan pada pasien laki-laki dan perempuan hampir seimbang (Harigustian, 2016).

Kasus Gagal Jantung Kongestif yang diteliti sebagian besar berumur antara 45 sampai dengan 65 tahun (42 kasus). Kasus Gagal Jantung meningkat seiring bertambahnya usia seseorang. Hal ini terjadi karena semakin tua usia, maka semakin besar kemungkinan penurunan fungsi jantung. Penelitian Harigustian (2016) di RS PKU Muhammadiyah Gamping mendapatkan hasil bahwa kasus gagal jantung terbanyak pada usia 61-65 tahun. Pada penelitian ini, kategori umur 66-85 tahun dan >85 tahun berjumlah lebih sedikit. Hal ini mengingat umur harapan hidup di Indonesia untuk laki-laki 69,44 tahun dan perempuan 73,33 tahun (BPS, 2021). 
Sedangkan selisih tarif rumah sakit dan tarif Ina CBGs ditunjukkan pada tabel di bawah :

Tabel 1. Selisih Tarif Rumah Sakit dan Tarif Ina CBGs

\begin{tabular}{lrrr}
\hline & $\begin{array}{c}\text { Tarif Ina } \\
\text { CBGs }\end{array}$ & Tarif RS & \multicolumn{1}{c}{$\begin{array}{c}\text { Selisih } \\
\text { Tarif }\end{array}$} \\
\hline Jumlah & 242.948 .200 & 283.106 .630 & - \\
\hline Rata-rata & 3.470 .688 & 4.044 .380 & -573.691 \\
\hline Std.Dev & 651.152 & 3.070 .192 & 2.825 .013 \\
\hline Angka & & & $116 \%$ \\
Indeks & & & \\
\hline
\end{tabular}

Berdasarkan tabel di atas, dapat dilihat bahwa terdapat selisih tarif bernilai negatif sebesar -40.158.430 dengan rata-rata selisih sebesar $-573.691 \pm 2.825 .013$. Tarif Rumah sakit lebih besar $16 \%$ dari pada tarif Ina CBGs, sehingga terdapat selisih negative yang cukup besar. Selisih tarif negatif ini dapat menimbulkan dampak kerugian pada rumah sakit. Dalam program JKN, rumah sakit mempunyai peluang untuk memanfaatkan selisih klaim yang bernilai positif. Namun jika pelayanan yang diberikan belum efektif dan efisien, akan berdampak pada selisih negatif klaim sehingga dapat menjadi ancaman terhadap pengelolaan keuangan rumah sakit (Mardiah, 2016). Cleverly dalam Agustin (2013) menyebutkan bahwa terdapat empat cara untuk pengendalian biaya paket (Cased Base Group), yaitu mengurangi harga yang harus dibayar pada sumber daya, mengurangi lama hari rawat, mengurangi intensitas pelayanan yang disediakan, dan meningkatkan efisiensi produksi. Sedangkan Chang dalam Rahayuningrum (2017) menyebutkan bahwa efisiensi RS dapat dilakukan dengan persaingan, pemakaian tempat tidur, jumlah dokter, jumlah perawat, pemakaian tekhnologi, struktur keluarga, lama hari perawatan, serta kebijakan kesehatan.

Komponen pembentuk tarif rumah sakit perlu dianalisis untuk mengetahui komponen dengan pembiayaan yang tinggi.
Tabel 2 menunjukkan besar dan prosentase biaya pada tiap komponen pembentuk tarif rumah sakit, sebagai berikut :

Tabel 2. Komponen Tarif Rumah Sakit

\begin{tabular}{lrr}
\hline \multicolumn{1}{c}{ Komponen Tarif } & \multicolumn{1}{c}{ Jumlah } & \multicolumn{1}{c}{$\%$} \\
\hline Prosedur non bedah & 22.526 .300 & 8,0 \\
\hline Biaya konsultasi & 19.418 .500 & 6,9 \\
\hline Biaya keperawatan & 388.047 & 0,1 \\
\hline Biaya penunjang & 6.268 .000 & 2,2 \\
\hline Biaya radiologi & 19.295 .000 & 6,8 \\
\hline Biaya laboratorium & 29.387 .700 & 10,4 \\
\hline Biaya kamar & 96.380 .407 & 34,0 \\
\hline Biaya rawat intensif & 350.000 & 0,1 \\
\hline Biaya obat & 60.902 .770 & 21,5 \\
\hline Biaya alkes & 12.976 .419 & 4,6 \\
\hline Biaya BMHP & 6.440 .587 & 2,3 \\
\hline Biaya sewa alat & 8.745 .000 & 3,1 \\
\hline & 283.078 .730 & 100 \\
\hline
\end{tabular}

Dari tabel di atas, dapat dilihat bahwa ada dua komponen besar pembentuk tarif rumah sakit, yaitu biaya kamar (34\%) dan biaya obat (21,5\%). Puspandari (2015) menyebutkan bahwa biaya obat memiliki proporsi sekitar $17 \%$ pada fasilitas pelayanan swasta. Penelitian Dumaris (2016) tentang perbedaan tarif di RSUD Budi Asih mendapatkan hasil bahwa biaya obat merupakan komponen terbesar dari tarif rumah sakit. Untuk mengatasi selisih tarif negatif, dilakukan efisiensi penggunaan obat, diantaranya : (1) proses perencanaan mengutamakan penggunaan obat-obat generik dan proses pembelian obat dengan e-catalogue untuk mengontrol harga obat, (2) melakukan sosialisasi standar formularium obat, (3) menetapkan plafon obat dan standar alat kesehatan, (4) efisiensi pemeriksaan laboratorium sesuai indikasi, (5) melakukan pengaturan item-item pada paket tindakan (Dumaris, 2016).

Biaya kamar merupakan komponen tertinggi dari tarif rumah sakit yang diteliti. Besarnya biaya kamar tergantung pada kelas perawatan dan lama hari rawat (LOS). Besar tarif Ina CBGs akan berbeda sesuai kelas rawat, namun tidak memperhitungkan lama hari rawat. 
Mengetahui komponen dengan selisih tarif yang tinggi berdasarkan severity level, kelas rawat, lama hari rawat, jumlah tindakan dan diagnosa sekunder diperlukan untuk menganalisis lebih mendalam perbedaan tarif rumah sakit dengan tarif Ina CBGs. Analisis dengan menggunakan angka indeks tertimbang berdasarkan kategori tinggi, sedang dan rendah digunakan untuk menganalisis komponen dengan selisih biaya yang tinggi. Hasil perhitungan ditunjukkan pada tabel 3, sebagai berikut:

Tabel 3. Selisih Tarif Berdasarkan Severity Level, Kelas Rawat, LOS, Tindakan dan Diagnosa Sekunder

\begin{tabular}{|c|c|c|c|c|c|c|}
\hline & Tarif RS & Tarif Ina CBGs & Selisih & $\begin{array}{l}\text { Rata-rata } \\
\text { Selisih }\end{array}$ & $\begin{array}{l}\text { Angka Index } \\
\text { Tertimbang }\end{array}$ & Kategori \\
\hline \multicolumn{7}{|l|}{ Severity Level } \\
\hline $\mathrm{I}(\mathrm{n}=33)$ & 110.106 .494 & 103.463.700 & -6.642 .79 & -201.296 & $124 \%$ & rendah \\
\hline II $(n=27)$ & 113.408 .864 & 95.941 .500 & -17.467 .36 & -646.939 & $137 \%$ & sedang \\
\hline $\mathrm{III}(\mathrm{n}=10)$ & 59.591 .272 & 43.543 .000 & -16.048 .27 & -1.604 .827 & $159 \%$ & sedang \\
\hline \multicolumn{7}{|l|}{ Kelas Rawat } \\
\hline $1(n=20)$ & 113.144.207 & 83.636 .000 & -29.508 .207 & -1.475 .410 & $157 \%$ & sedang \\
\hline $2(\mathrm{n}=20)$ & 76.083 .172 & 69.474 .000 & -6.609 .172 & -330.458 & $127 \%$ & rendah \\
\hline $3(n=30)$ & 93.879.251 & 89.838 .200 & -4.041 .051 & -134.701 & $121 \%$ & rendah \\
\hline \multicolumn{7}{|l|}{ LOS } \\
\hline $\begin{array}{r}\leq 5 \text { hari } \\
(n=45)\end{array}$ & 119.340 .600 & 148.914 .900 & 29.574 .300 & 657.206 & $93 \%$ & rendah \\
\hline $\begin{array}{r}>5 \text { hari } \\
(\mathrm{n}=25)\end{array}$ & 163.766 .030 & 94.033 .300 & -69.732 .730 & -2.789 .309 & $202 \%$ & tinggi \\
\hline \multicolumn{7}{|l|}{ Tindakan } \\
\hline$\geq 1(n=43)$ & 60.964 .384 & 86.859 .700 & 25.895 .316 & 959.085 & $81 \%$ & rendah \\
\hline$<1(\mathrm{n}=27)$ & 222.142.246 & 156.088 .500 & -66.053 .746 & -1.536 .133 & $165 \%$ & tinggi \\
\hline \multicolumn{7}{|c|}{ Diagnosa Sekunder } \\
\hline Kode diag. I & 81.350 .443 & 77.065 .700 & -4.284 .743 & -194.761 & $123 \%$ & rendah \\
\hline Selain kode I & 201.756.187 & 165.882 .500 & -35.873 .687 & -747.368 & $141 \%$ & sedang \\
\hline
\end{tabular}

Dari tabel diatas dapat terlihat bahwa tarif rumah sakit lebih tinggi dari pada tarif Ina CBGs dengan selisih yang tinggi pada lama hari rawat $($ LOS $)>5$ hari dan Tindakan $<1$, sedangkan variabel lainnya termasuk kategori rendah dan sedang. Lama hari rawat $>5$ hari menyebabkan tarif rumah sakit lebih besar dari tarif Ina CBGs sebesar $102 \%$. Lama hari rawat $>5$ hari menjadi faktor yang paling besar menyebabkan selisih tarif. Penelitian ini senada dengan penelitian Puspandari (2015) dan Rahayuningrum (2017) dimana lama hari rawat dapat mempengaruhi pembiayaan di rumah sakit.

Lama hari rawat dapat mempengaruhi perbedaan tarif rumah sakit dengan tarif Ina
CBGs. Hal tersebut dikarenakan lama hari rawat pada tarif rumah sakit dihitung per hari, sehingga semakin lama pasien dirawat semakin besar pula biayanya. Sedangkan pada pada tarif Ina CBGs lama hari rawat sudah ditentukan standarnya, sehingga besarnya biaya akan sama meskipun lama hari rawat berbeda (Wijayanti, 2013). Lama hari rawat berimplikasi pada peningkatan tarif rumah sakit karena pelayanan kesehatan yang diberikan menjadi lebih banyak, bahkan dapat jadi sia-sia. Hal ini dapat menimbulkan alokasi dana dan sumberdaya kurang efisien. Menghubungkan antara efisiensi dan pembiayaan akan mendorong rumah sakit 
untuk melakukan peningkatan efisiensi (Rahayuningrum, 2017).

Peningkatan efisiensi dapat dilakukan dengan menerapkan clinical pathway sebagai sarana pengendali dan standar pemberian pelayanan kesehatan. Penggunaan clinical pathway kasus jantung dapat mengurangi lama hari rawat dan biaya kesehatan hingga 20\% (You, 2017). Belum ada penegakan clinical pathway pada kasus gagal jantung kongesif di rumah sakit $\mathrm{X}$.

Tarif rumah sakit lebih tinggi dari tarif Ina CBGs dengan selisih yang tinggi pada banyaknya tindakan dalam penanganan kasus kegagalan jantung. Tarif rumah sakit lebih tinggi $65 \%$ daripada tarif Ina CBGs pada penanganan gagal jantung dengan lebih dari satu tindakan. Jika pasien hanya mendapatkan satu tindakan (EKG) atau tanpa tindakan, maka tarif rumah sakit lebih rendah 19\% dari tarif Ina CBGs. Namun jika dilakukan tindakan lain selain EKG, maka tarif rumah sakit jauh lebih tinggi dari tarif Ina CBGs. Tindakan yang semakin banyak akan membutuhkan biaya pemeriksaan yang semakin besar pula (Sari, 2020).

Dengan menerapkan clinical pathway pada penanganan kasus gagal jantung kongesif ini, efisiensi pelayanan dapat dilakukan tanpa menurunkan mutu pelayanan. Clinical pathway untuk manajemen penyakit akut dan kronis terbukti efektif dalam mengurangi kunjungan ulang ke rumah sakit, meningkatkan hasil pelayanan kesehatan dan mengurangi biaya rumah sakit. Clinical pathway untuk penanganan kasus gagal jantung kongesif terbukti efektif dalam menurunkan lama rawat di rumah sakit (Moore, 2016).

Penggunaan clinical pathway merupakan salah satu cara mengatasi selisih biaya rumah sakit. Clinical pathway berisi langkahlangkah penanganan pasien yang terdiri atas protokol terapi dan standar pelayanan pasien mulai dari masuk sampai dengan keluar rumah sakit. Penerapan clinical pathway meningkatkan efisiensi penggunaan lama hari dirawat tanpa mengurangi kualitasnya. Clinical Pathway merupakan salah satu cara untuk kendali mutu dan kendali biaya. Dengan adanya clinical pathway, maka besarnya biaya pengobatan dan perawatan dapat diprediksikan secara tepat (Agiwahyuanto, 2020).

\section{Simpulan dan Saran}

Perbedaan tarif rumah sakit dengan tarif Ina CBGs di rumah sakit $X$ pada bulan Oktober - Desember 2019 menyebabkan adanya selisih negative sebesar -40.158 .430$ dengan rata-rata selisih sebesar $-573.691 \pm$ 2.825.013. Selisih negative ini dapat menimbulkan dampak kerugian bagi rumah sakit. Tarif rumah sakit lebih tinggi dari pada tarif Ina CBGs dengan nilai selisih yang tinggi pada lama hari rawat $>5$ hari $(102 \%)$, dan jumlah tindakan lebih dari satu tindakan (65\%). Menegakkan clinical pathway untuk penanganan kasus gagal jantung kongesif diperlukan untuk meningkatkan efisiensi lama hari dirawat dan mengurangi tindakan yang kurang dibutuhkan tanpa mengurangi kualitas pelayanan.

\section{Ucapan Terima Kasih}

Terima kasih disampaikan kepada seluruh pihak yang turut serta membantu terlaksananya penelitian ini.

\section{Daftar Pustaka}

Adhi Mahabudi Duarsa, Wahyu Sulistiadi, Ismail Sangadji. (2019). Strategi Atasi Perbedaan Unit Cost Sectio Caesaria dengan Klaim berdasarkan Tarif INACBG's pada Pasien BPJS di Rumah Sakit Khusus Ibu Dan Anak Bunda Liwa. Jurnal Manajemen Dan Administrasi Rumah Sakit Indonesia. Vol 3 No 2 Oktober 2019. E-ISSN: 26856328 P-ISSN: 2685-6298 
Agustin Ika Wijayanti, Sri Sugiarsi. (2013). Analisis perbedaan tarif riil dengan tarif paket Ina CBG pada pembayaran klaim jamkesmas pasien rawat inap di RSUD Kabupaten Sukoharjo. JMIKI: Vol.1 No.1 tahun 2013.

Amy A. Yau, Long T. Nguyendo, LaKeesha L. Lockett, et al. (2017). The hearth pathway and hospital cost savings. Crit Pathways in Cardiol 2017;16: 126128.

Badan Pusat Statistik. (2021). Indikator strategis nasional. bps.go.id. diakses pada 14 Februari 2021.

Dewi Pramesti Cahyani, Muhammad Akib Yuswar, Nurmainah. (2019). Analisis kesesuaian biaya riil terhadap tarif ina-cbgs pada pengobatan stroke iskemik pasien $\mathrm{jkn}$ rawat inap RSUD Sultan Syarif Mohamad Alkadrie Pontianak tahun 2018. Jurnal Mahasiswa Farmasi Kedokteran UNTAN. Vol 4 No 1 tahun 2019.

Diah Ayu Puspandari, Ali Ghufron Mukti, Hari Kusnanto. (2015). Faktor-faktor yang mempengaruhi biaya obat pasien kanker payudara di rumah sakit di Indonesia. Jurnal Kebijakan Kesehatan Indonesia: Vol. 04 No. 03 September 2015:104 - 108.

Faik Agiwahyuanto, Evina Widianawati, Widya Ratna Wulan, Rizqi Basuki Putri. (2020). Tarif rumah sakit dengan tarif Ina-CBGs pasien rawat inap. Higiea: Vol.4 No.4.

Gigih Kenanga Sari, Mingle A Pistanty, Wahyu Purwanjani. (2020). Analisis biaya pasien gagal jantung rawat inap jamkesmas di RSUP dr. Sardjito Yogyakarta. Journal of TSCD3Kep: Vol.5 No.2.

Heniwati, Hasbullan Thabrany. (2016). Perbandingan Klaim Penyakit Katastropik Peserta Jaminan Kesehatan Nasional di Provinsi DKI Jakarta dan Nusa Tenggara Timur Tahun 2014. Jurnal Ekonomi Kesehatan Indonesia. Vol 1 N0 2 Nopember 2016.
Hotma Dumaris. (2016). Analisis perbedaan tarif rumah sakit dan tarif Ina-CBG's pelayanan rawat jalan di RSUD Budhi Asih Jakarta tahun 2015. Jurnal ARSI: Vol.3 No.1 tahun 2016.

Indriyati Oktaviano Rahayuningrum, Didik Gunawan Tamtomo, Arief Suryono. (2017). Analisis tarif rumah sakit dibandingkan dengan tarif indonesian case based groups pada pasien rawat inap peserta jaminan kesehatan nasional di rumah sakit. Prosiding Seminar Nasional dan Internasional Universitas Muhammadiyah Semarang.

Jo-Ann Mary Moore. (2016). Evaluation of the efficacy of a nurse practitioner-led home-based congestive hearth failure clinical pathway. Home Health Care Services Quarterly.

Lailia Nur Rachma. (2014). Patomekanisme penyakit gagal jantung kongestif. ElHayah. Vol. 4, No.2 Maret 2014.

Laksono Trisnantoro. (2016). Memahami penggunaan ilmu ekonomi dalam manajemen rumah sakit. Gadjah Mada University Press. ISBN: 979-420-541-9

Mardiah. (2016). Cost recovery rate tarif rumah sakit dan tarif INA-CBG's berdasarkan clinical pathway pada penyakit arteri koroner di RSUP Dr. Mohammad Hoesin Palembang Tahun 2015. Jurnal ARSI: Vol 2 No 3 Juni 2016.

Noor Aisyah, Tri Murti Andayani, Diah Ayu Puspandari. (2018). Analisis biaya kemoterapi pada pasien rawat inap kanker payudara peserta jkn di RSUD Ulin Banjarmasin. Jurnal Ilmiah Ibnu Sina. Vol 2 No 2 hal 333-342.

Putra PRS, Indar dan Jafar N. (2014). Ability to pay dan catastrophic payment pada peserta pembayar mandiri bpjs kesehatan kota makassar. Jurnal Kesehatan, 4 (3 ): 283 - 290 
Ratih Pratiwi Sari. (2014). Perbandingan biaya riil dengan tarif paket Ina CBGs dan analisa faktor yang mempengaruhi biaya riil pada pasien diabetes mellitus rawat inap Jamkesmas di RSUP Dr. Sardjito Yogyakarta.

Yayang Harigustian, Arlina Dewi, Azizah Khoiriyati. (2016). Gambaran Karakteristik Pasien Gagal Jantung Usia 45 - 65 Tahun di Rumah Sakit PKU Muhammadiyah Gamping Sleman. Indonesian Journal of Nursing Practices: Vol.1 No.1 Desember 2016. 